\title{
The Singapore Statement on Research Integrity
}

\author{
David B. Resnik, J.D., Ph.D. ${ }^{1}$ and Adil E. Shamoo, Ph.D. ${ }^{2}$ \\ ${ }^{1} \mathrm{NIEHS} / \mathrm{NIH}$, Research Triangle Park, North Carolina, USA \\ ${ }^{2}$ University of Maryland School of Medicine, Baltimore, Maryland, USA
}

\section{Keywords}

Singapore Statement; research integrity; ethics; international research

The Singapore Statement on Research Integrity, drafted at the Second World Conference on Research Integrity, which took place in Singapore from July 21 to 24, 2010, is an important step toward promoting ethical conduct among scientists around the world. The 340 conference attendees included scientists, journal editors, academic and industry leaders, and representatives from government funding agencies and publishers from over 51 countries. Nanyang Technological University, the National University of Singapore, the Singapore Management University, and the Agency for Science, Technology, and Research hosted the gathering, with support from Singapore's Ministry of Education and National Research Foundation. The Singapore statement was drafted by conference co-chairs, Nicholas Steneck (University of Michigan) and Tony Mayer (Nanyang Technological University), and the incoming chair for the next World Conference, Melissa Anderson (University of Minnesota). In contrast to the First World Conference, which took place in Lisbon, Portugal in 2007 and focused on misconduct issues, the goal of the Second World Conference was to make a concerted effort to promote global research integrity (Kleinert, 2010a,b). The Singapore Statement is the fruit of this endeavor.

One of the difficulties with promoting global scientific integrity is that there are social, political, cultural, and economic differences among nations that affect the conduct of research and influence ethical norms (Resnik, 2009). In its preamble, the Singapore Statement acknowledges these differences, but maintains that there are some common standards for research ethics that transcend national boundaries. The Singapore Statement is not a regulatory document and does not represent the official policies of the countries represented at the conference. Rather, the intent of the Singapore Statement is to provide ethical guidance which research organizations, governments, and scientists can use to develop policies, regulations, and codes of conduct (World Conference on Research Integrity, 2010).

The Singapore Statement includes four principles—-honesty, accountability, professionalism, and stewardship —and fourteen responsibilities for the ethical conduct of research. The responsibilities address such topics as data integrity, data sharing, record keeping, authorship, publication, peer review, conflict of interest, reporting misconduct and irresponsible research, communicating with the public, complying with regulations, education, and social responsibilities (World Conference on Research Integrity, 2010).

Copyright $(\subseteq$ Taylor \& Francis Group, LLC

Address correspondence to David B. Resnik, NIEHS/NIH, Box 12233, MD CU-03, Research Triangle Park, NC 27709, USA. resnikd@ niehs.nih.gov. 
These principles and responsibilities are comprehensive, clear, and thoughtful, and they can play an important role in promoting global research integrity. (The full text of the Singapore Statement is printed in the Appendix of this article.)

Because research often involves collaborations among investigators, laboratories, and institutions from different countries, it is important for the scientific community to establish and follow international integrity standards (Resnik, 2009). International incidents, such as fraudulent papers published in Science by South Korean stem cell researcher Woo Suk Hwang (Resnik et al., 2006), illustrate vividly the need for global guidelines. For many years, there have been widely recognized international standards for conducting research with human subjects, such as the Nuremberg Code (1949) Helsinki Declaration (World Medical Association, 2008), and the Council for the International Organizations of Medical Sciences (2002) guidelines. These influential documents have helped guide the development of laws, regulations, and guidelines adopted by different countries, institutions, industry groups, and funding agencies. Similarly, the Singapore Statement can play a similar role in shaping the development of national and local rules and guidelines for research integrity.

For the Singapore Statement to have a lasting impact on global research integrity, scientists and policymakers should read the document carefully and reflect on its implications for the conduct of research. Universities, journals, funding agencies, and other scientific organizations should promote the Singapore Statement by publicly endorsing it and developing rules and guidelines for ethical conduct consistent with its principles. Likewise, professional organizations should also consider endorsing the Singapore Statement and referring to it when drafting or revising their ethics codes and policies. Teachers and mentors should make students and trainees aware of the Singapore Statement when providing education and training on the responsible conduct of research. Research organizations should sponsor conferences or workshops to address the Singapore Statement. While the Singapore Statement provides a useful framework for promoting global research integrity, its goals will not be achieved until its principles and responsibilities are adopted and put into practice.

\section{Acknowledgments}

This research was supported by the National Institute of Environmental Health Sciences (NIEHS), National Institutes of Health (NIH). It does not represent the views of the NIEHS, NIH, or U.S. government.

\section{APPENDIX: SECOND WORLD CONFERENCE ON RESEARCH INTEGRITY: THE SINGAPORE STATEMENT ON RESEARCH INTEGRITY (PUBLISHED WITH PERMISSION)}

\section{Preamble}

The value and benefits of research are vitally dependent on the integrity of research. While there can be and are national and disciplinary differences in the way research is organized and conducted, there are also principles and professional responsibilities that are fundamental to the integrity of research wherever it is undertaken.

\section{Principles}

Honesty in all aspects of research

Accountability in the conduct of research 
Professional courtesy and fairness in working with others

Good stewardship of research on behalf of others

\section{Responsibilities}

1. Integrity: Researchers should take responsibility for the trustworthiness of their research.

2. Adherence to Regulations: Researchers should be aware of and adhere to regulations and policies related to research.

3. Research Methods: Researchers should employ appropriate research methods, base conclusions on critical analysis of the evidence, and report findings and interpretations fully and objectively.

4. Research Records: Researchers should keep clear, accurate records of all research in ways that will allow verification and replication of their work by others.

5. Research Findings: Researchers should share data and findings openly and promptly, as soon as they have had an opportunity to establish priority and ownership claims.

6. Authorship: Researchers should take responsibility for their contributions to all publications, funding applications, reports, and other representations of their research. Lists of authors should include all those and only those who meet applicable authorship criteria.

7. Publication Acknowledgment: Researchers should acknowledge in publications the names and roles of those who made significant contributions to the research, including writers, funders, sponsors, and others, but do not meet authorship criteria.

8. Peer Review: Researchers should provide fair, prompt, and rigorous evaluations and respect confidentiality when reviewing others' work.

9. Conflict of Interest: Researchers should disclose financial and other conflicts of interest that could compromise the trustworthiness of their work in research proposals, publications, and public communications as well as in all review activities.

10. Public Communication: Researchers should limit professional comments to their recognized expertise when engaged in public discussions about the application and importance of research findings and clearly distinguish professional comments from opinions based on personal views.

11. Reporting Irresponsible Research Practices: Researchers should report to the appropriate authorities any suspected research misconduct, including fabrication, falsification, or plagiarism, and other irresponsible research practices that undermine the trustworthiness of research, such as carelessness, improperly listing authors, failing to report conflicting data, or the use of misleading analytical methods.

12. Responding to Irresponsible Research Practices: Research institutions, as well as journals, professional organizations, and agencies that have commitments to research, should have procedures for responding to allegations of misconduct and other irresponsible research practices and for protecting those who report such behavior in good faith. When misconduct or other irresponsible research practice is 
confirmed, appropriate actions should be taken promptly, including correcting the research record.

13. Research Environments: Research institutions should create and sustain environments that encourage integrity through education, clear policies, and reasonable standards for advancement, while fostering work environments that support research integrity.

14. Societal Considerations: Researchers and research institutions should recognize that they have an ethical obligation to weigh societal benefits against risks inherent in their work.

\section{REFERENCES}

Council for International Organisations of Medical Sciences. [Last accessed December 21, 2010] International Ethical Guidelines for Biomedical Research Involving Human Subjects. 2002. Available at http://www.cioms.ch/frame_guidelines_nov_2002.htm

Kleinert S. Singapore embraces international research integrity. The Lancet. 2010a; 376:400-401.

Kleinert S. Singapore Statement: A global agreement on responsible research conduct. The Lancet. 2010b; 376:1125-1127.

Nuremberg Code. Trials of War Criminals before the Nuremberg Military Tribunals under Control Council Law. Vol. Vol. 2. U.S. Government Printing Office; Washington, D.C.: 1949. p. 181-182.Available at http://ohsr.od.nih.gov/guidelines/nuremberg.html [Last accessed December $21,2010]$

Resnik DB. International standards for research integrity: An idea whose time has come? Accountability in Research. 2009; 16:218-228. [PubMed: 20183162]

Resnik DB, Shamoo AE, Krimsky S. Fraudulent human embryonic stem cell research in South Korea: Lessons learned. Accountability in Research. 2006; 13:101-109. [PubMed: 16770863]

World Conference on Research Integrity. [Last accessed December 21, 2010] Singapore Statement. 2010. Available at http://www.singaporestatement.org/statement.html

World Medical Association. [Last accessed December 21, 2010] Declaration of Helsinki: Ethical Principles for Medical Research Involving Human Subjects. 2008. Available at http:// www.wma.net/e/ policy/b3.htm 